\title{
Computed tomography morphometric analysis for lateral mass screw placement in the pediatric subaxial cervical spine
}

\author{
Clinical article
}

\author{
George Al-Shamy, M.D., ${ }^{1}$ Jacob Cherian, M.D., ${ }^{1}$ Javier A. Mata, M.D. ${ }^{1}$ \\ Akash J. Patel, M.D., ${ }^{1}$ Steven W. Hwang, M.D., ${ }^{2}$ and Andrew Jea, M.D. 1
}

${ }^{I}$ Neuro-Spine Program, Division of Pediatric Neurosurgery, Texas Children's Hospital, and Department of Neurosurgery, Baylor College of Medicine, Houston, Texas; and ${ }^{2}$ Division of Pediatric Neurosurgery, Floating Children's Hospital, Department of Neurosurgery, Tufts University, Boston, Massachusetts

\begin{abstract}
Object. Lateral mass screws are routinely placed throughout the subaxial cervical spine in adults, but there are few clinical or radiographic studies regarding lateral mass fixation in children. The morphology of pediatric cervical lateral masses may be associated with greater difficulty in obtaining adequate purchase. The authors examined the lateral masses of the subaxial cervical spine in pediatric patients to define morphometric differences compared with adults, establish guidelines for lateral mass instrumentation in children, and define potential limitations of this technique in the pediatric age group.

Methods. Morphometric analysis was performed on CT of the lateral masses of C3-7 in 56 boys and 14 girls. Measurements were obtained in the axial, coronal, and sagittal planes.

Results. For most levels and measurements, results in boys and girls did not differ significantly; the few values that were significantly different are not likely to be clinically significant. On the other hand, younger $(<8$ years of age) and older children ( $\geq 8$ years of age) differed significantly at every level and measurement except for facet angularity. Sagittal diagonal, a measurement that closely estimates screw length, was found to increase at each successive caudal level from C-3 to C-7, similar to the adult population. A screw acceptance analysis found that all patients $\geq 4$ years of age could accept at least a $3.5 \times 10 \mathrm{~mm}$ lateral mass screw.

Conclusions. Lateral mass screw fixation is feasible in the pediatric cervical spine, particularly in children age 4 years old or older. Lateral mass screw fixation is feasible even at the C-7 level, where pedicle screw placement has been advised in lieu of lateral mass screws because of the small size and steep trajectory of the C-7 lateral mass. Nonetheless, all pediatric patients should undergo high-resolution, thin-slice CT preoperatively to assess suitability for lateral mass screw fixation.

(http://thejns.org/doi/abs/10.3171/2012.8.SPINE12767)
\end{abstract}

KEY Words - cervical spine • lateral mass $\bullet \quad$ screw fixation $\bullet \quad$ pediatric spine

$\mathrm{R}$ OY-CAMILlE ${ }^{12-14}$ first described the use of lateral mass screw fixation for cervical spine stabilization. Roy-Camille, Magerl, and Louis ${ }^{9,10,13}$ popularized this safe and efficacious way of achieving rigid cervical fixation. The lateral mass is a pillar of bone that offers safe purchase for screw fixation in the pediatric cervical spine that is otherwise not suitable for other types of fixation, such as pedicle screws. ${ }^{8}$ Complications related to screw malposition are usually due to the close proximity of exiting cervical nerve roots and the vertebral artery. ${ }^{19}$ Although this technique has been established as a safe approach in many large series of adult patients, $,, 13,15,17$ little has been published in the pediatric spine literature regarding the safety and feasibility of lateral mass screw fixation of the cervical spine in children. ${ }^{8}$
It is widely assumed that pediatric cervical lateral masses differ in anatomical dimensions from their adult counterparts. Abdullah et al. ${ }^{1}$ recently published a morphometric and volumetric analysis of the lateral masses of the adult lower cervical spine (C5-7). To the best of our knowledge, there has been no such study attempting to reconcile differences between pediatric and adult lateral masses with modified versions of established surgical techniques. ${ }^{3,4,16,18}$ We performed a CT-based morphometric study of the pediatric subaxial cervical spine to determine the feasibility of cervical lateral mass screw

This article contains some figures that are displayed in color online but in black-and-white in the print edition. 
placement in the pediatric population and to establish placement guidelines.

\section{Methods}

\section{Study Population}

A morphometric analysis of the subaxial cervical spine lateral masses (C3-7) was performed in 70 pediatric patients. There were 56 boys and 14 girls included in our analysis. The mean age of the patients was 4.93 years (range 2 months to 16 years). Patients were selected from children who underwent a CT scan of the cervical spine at Texas Children's Hospital between August 2006 and February 2011. Exclusion criteria included patients greater than 18 years of age, congenital deformities of formation or segmentation of the cervical spine, and radiographic evidence of trauma, neoplastic or inflammatory disease, infection, or previous surgery.

\section{Lateral Mass Measurements}

Linear and angular measurements were obtained with the standard measurement palette in our picture archiving and communications system (Philips iSite). Linear measurements were automatically rounded to the nearest 0.1 $\mathrm{mm}$. Angular measurements were automatically rounded to the nearest degree. All measurements were obtained bilaterally. Comparisons based on age were recorded.

Multiple measurements (in millimeters) in axial, coronal, and sagittal planes were obtained from CT scans with a resolution of $5 \mathrm{~mm}$ or less as previously described. ${ }^{2}$ In the axial plane, measurements were obtained from the medial to lateral cortex and from dorsal to ventral cortices through the center of the lateral mass at the level of the pedicle (Fig. 1A). In the coronal plane, the width measurement was made at the center of the lateral mass originating at the lateral cortex of the lateral mass and terminating at the laminofacet line, and coronal height was measured from successive facet joint to facet joint (Fig. 1B). Sagittal width was measured through the center of the lateral mass just above the level of the pedicle from the dorsal to ventral cortices, and sagittal height was measured as the anatomical height at the center of the lateral mass. The diagonal measurement in the sagittal plane started at the superior articular process and terminated at the inferior articular process (Fig. 1C). The measure of facet angularity was the magnitude of the angle created by the vertex of 2 traced lines in the sagittal plane: the superior border of the superior articular process and the level of the pedicle (Fig. 1D).

\section{Statistical Analysis}

Statistical analysis was performed using SPSS (SPSS Inc.). Descriptive statistics including mean, standard deviation, standard error, and confidence intervals were computed for all measurements, and probability values were calculated using the Student t-test and were considered significant at $<0.05$.

\section{Results}

For our cohort, we determined which patients could
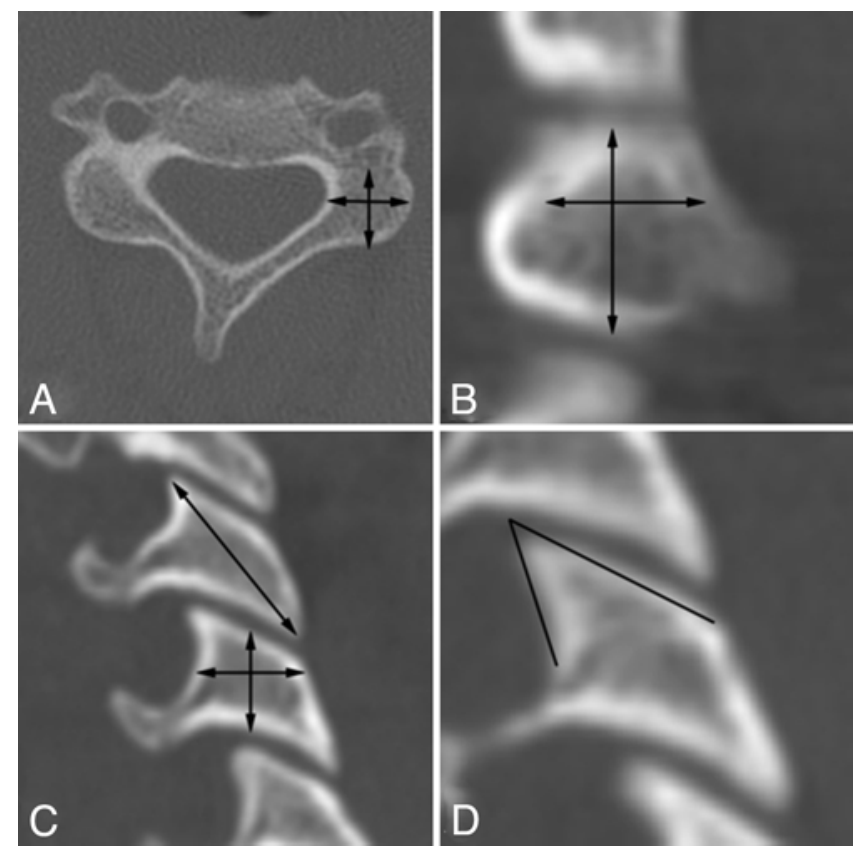

Fig. 1. Schematic view of morphometric measurements. A: Axial section of lateral mass showing width and height measurements. B: Coronal width and height of lateral mass with transverse process in plane. C: Sagittal measurements of thickness and anatomical and diagonal height. D: Measurement of facet angularity in the sagittal plane.

accept a lateral mass screw at each cervical level, from C-3 to C-7 (Fig. 2). We assumed the smallest commercially available lateral mass screw was $10 \mathrm{~mm}$ in length and $3.5 \mathrm{~mm}$ in diameter; thus, any patient who had any linear dimension less than $4.0 \mathrm{~mm}$, assuming a $0.5 \mathrm{~mm}$ margin of safety, or sagittal diagonal less than $10 \mathrm{~mm}$ could not accept a screw at that level. In our cohort, only children younger than the age of 4 years had CT measurements that were too small for lateral mass screw placement. Of all the patients who were younger than 1 year of age, only 1 patient had all linear dimensions greater than $4.0 \mathrm{~mm}$. The mean optimal screw length, approximated by the sagittal diagonal, was $12.83 \pm 3.12 \mathrm{~mm}$ (range $6.5-25.5 \mathrm{~mm}$ ). Mean rostral angulation for lateral mass screw placement using the Magerl technique of paralleling the facet joints was $45^{\circ}$ (range $26^{\circ}-87^{\circ}$ ).

\section{Axial Width and Height}

The overall mean axial width from C-3 to C-7 was $8.57 \pm 1.57 \mathrm{~mm}, 8.49 \pm 1.47 \mathrm{~mm}, 8.63 \pm 1.55 \mathrm{~mm}, 8.41 \pm$ $1.53 \mathrm{~mm}$, and $8.23 \pm 1.51 \mathrm{~mm}$, respectively. There were statistically significant differences between boys and girls at C-6 and C-7. The mean axial width in patients younger than 8 years of age for levels C3-7 was $8.33 \pm 1.43 \mathrm{~mm}$, $8.31 \pm 1.33 \mathrm{~mm}, 8.32 \pm 1.24 \mathrm{~mm}, 8.13 \pm 1.24 \mathrm{~mm}$, and $7.96 \pm 1.18 \mathrm{~mm}$, respectively. For patients 8 years or older, the mean axial widths were $9.52 \pm 1.78 \mathrm{~mm}, 9.23 \pm 1.77$ $\mathrm{mm}, 9.93 \pm 2.00 \mathrm{~mm}, 9.56 \pm 2.04 \mathrm{~mm}$, and $9.38 \pm 2.14$ $\mathrm{mm}$, respectively. All of these differences were statistically significant (Table 1 ).

The overall mean axial height from $\mathrm{C}-3$ to $\mathrm{C}-7$ was $7.08 \pm 1.46 \mathrm{~mm}, 6.92 \pm 1.44 \mathrm{~mm}, 6.85 \pm 1.46 \mathrm{~mm}, 6.54 \pm$ 
G. Al-Shamy et al.
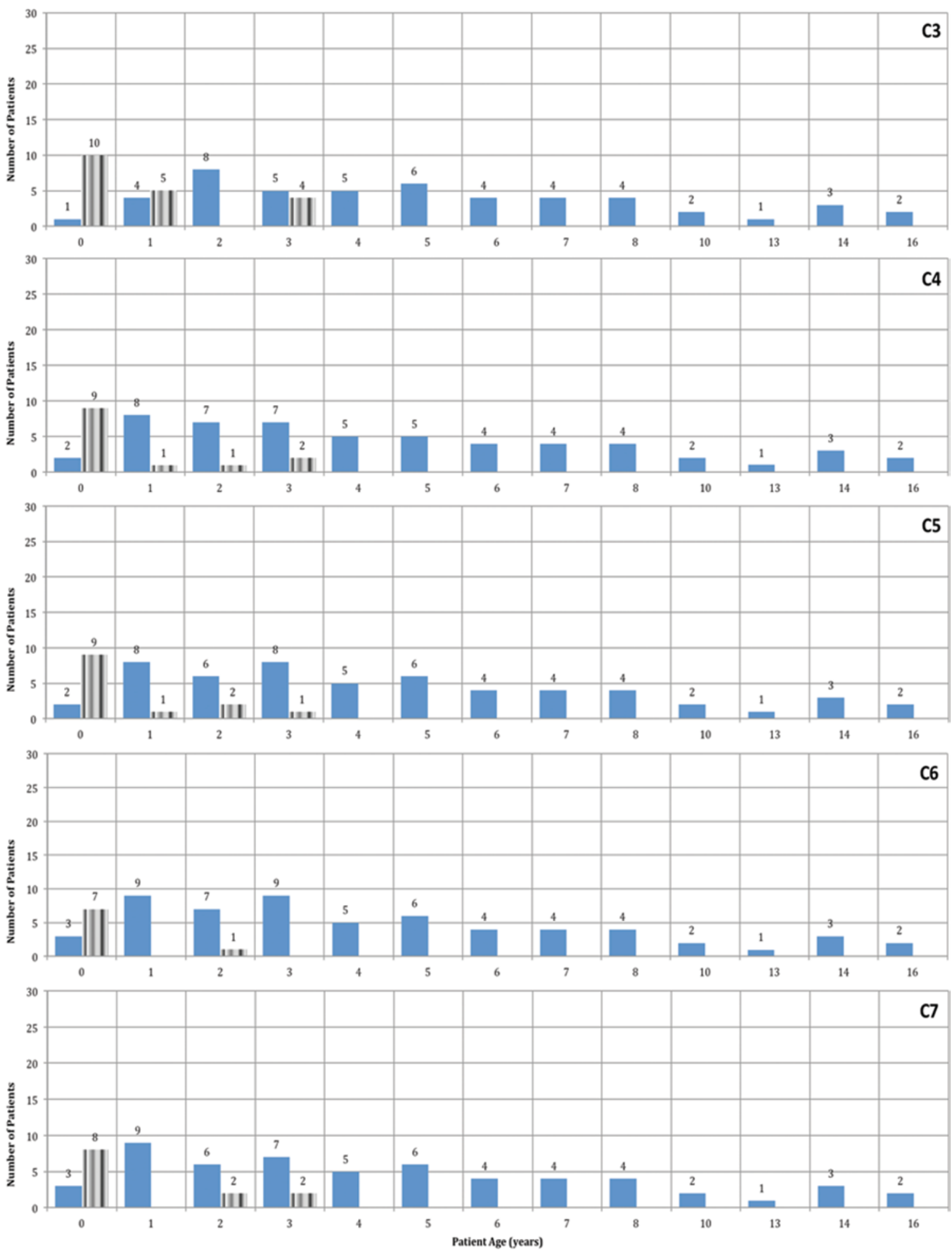

FIG. 2. Graph showing the distribution of patients whose anatomy was able to accept lateral mass screws at each level based on age. Blue bars represent those lateral masses that could accept a pedicle screw, gray bars represent those that could not.

$1.23 \mathrm{~mm}$, and $6.25 \pm 1.47 \mathrm{~mm}$, respectively. There were no statistically significant differences between boys and girls, except at C-7. The mean axial height in patients younger than 8 years of age for levels $\mathrm{C} 3-7$ was $6.76 \pm$ $1.20 \mathrm{~mm}, 6.62 \pm 1.16 \mathrm{~mm}, 6.50 \pm 1.15 \mathrm{~mm}, 6.30 \pm 1.13$ $\mathrm{mm}$, and $6.03 \pm 1.32 \mathrm{~mm}$, respectively. For patients 8 years or older, the mean axial height was $8.38 \pm 1.68 \mathrm{~mm}$, $8.17 \pm 1.80 \mathrm{~mm}, 8.29 \pm 1.73 \mathrm{~mm}, 7.53 \pm 1.12 \mathrm{~mm}$, and 7.19 $\pm 1.70 \mathrm{~mm}$, respectively. All of these differences were statistically significant (Table 1). 
Morphometric analysis of lateral masses

TABLE 1: Axial width and height in 70 patients stratified by age and sex*

\begin{tabular}{|c|c|c|c|c|c|c|c|}
\hline Vertebra & All & Male & Female & $p$ Value & Age $<8$ & Age $\geq 8$ & $p$ Value \\
\hline \multicolumn{8}{|l|}{ axial width } \\
\hline C-3 & $8.57 \pm 1.57$ & $8.73 \pm 1.56$ & $8.21 \pm 1.57$ & 0.0744 & $8.33 \pm 1.43$ & $9.52 \pm 1.78$ & 0.0022 \\
\hline C-4 & $8.49 \pm 1.47$ & $8.60 \pm 1.48$ & $8.24 \pm 1.43$ & 0.1817 & $8.31 \pm 1.33$ & $9.23 \pm 1.77$ & 0.0154 \\
\hline C-5 & $8.63 \pm 1.55$ & $8.71 \pm 1.61$ & $8.47 \pm 1.40$ & 0.3829 & $8.32 \pm 1.24$ & $9.93 \pm 2.00$ & 0.0003 \\
\hline C-6 & $8.41 \pm 1.53$ & $8.60 \pm 1.61$ & $8.00 \pm 1.27$ & 0.0200 & $8.13 \pm 1.24$ & $9.56 \pm 2.04$ & 0.0014 \\
\hline C-7 & $8.23 \pm 1.51$ & $8.44 \pm 1.53$ & $7.78 \pm 1.38$ & 0.0128 & $7.96 \pm 1.18$ & $9.38 \pm 2.14$ & 0.0028 \\
\hline \multicolumn{8}{|l|}{ axial height } \\
\hline C-3 & $7.08 \pm 1.46$ & $7.13 \pm 1.58$ & $6.96 \pm 1.14$ & 0.4582 & $6.76 \pm 1.20$ & $8.38 \pm 1.68$ & $<0.0001$ \\
\hline C-4 & $6.92 \pm 1.44$ & $6.97 \pm 1.48$ & $6.82 \pm 1.35$ & 0.5563 & $6.62 \pm 1.16$ & $8.17 \pm 1.80$ & $<0.0001$ \\
\hline C-5 & $6.85 \pm 1.46$ & $6.87 \pm 1.51$ & $6.79 \pm 1.36$ & 0.7513 & $6.50 \pm 1.15$ & $8.29 \pm 1.73$ & $<0.0001$ \\
\hline C-6 & $6.54 \pm 1.23$ & $6.62 \pm 1.31$ & $6.36 \pm 1.03$ & 0.2129 & $6.30 \pm 1.13$ & $7.53 \pm 1.12$ & $<0.0001$ \\
\hline C-7 & $6.25 \pm 1.47$ & $6.57 \pm 1.48$ & $5.55 \pm 1.18$ & $<0.0001$ & $6.03 \pm 1.32$ & $7.19 \pm 1.70$ & 0.0026 \\
\hline
\end{tabular}

* All data given as mean \pm SD (mm). Boldface type indicates statistical significance.

\section{Coronal Width and Height}

The overall mean coronal width from C-3 to C-7 was $8.67 \pm 1.67 \mathrm{~mm}, 8.68 \pm 1.62 \mathrm{~mm}, 8.55 \pm 1.53 \mathrm{~mm}, 8.43 \pm$ $1.70 \mathrm{~mm}$, and $9.39 \pm 2.26 \mathrm{~mm}$, respectively. There were no statistically significant differences between boys and girls, except at C-5. The mean coronal width in patients younger than 8 years of age for levels C3-7 was $8.38 \pm$ $1.38 \mathrm{~mm}, 8.43 \pm 1.37 \mathrm{~mm}, 8.28 \pm 1.32 \mathrm{~mm}, 8.05 \pm 1.34$ $\mathrm{mm}$, and $8.94 \pm 1.78 \mathrm{~mm}$, respectively. For patients 8 years or older, the mean coronal widths were $9.86 \pm 2.14$ $\mathrm{mm}, 9.72 \pm 2.14 \mathrm{~mm}, 9.69 \pm 1.83 \mathrm{~mm}, 10.04 \pm 2.09 \mathrm{~mm}$, and $11.35 \pm 2.98 \mathrm{~mm}$, respectively. All of these differences were statistically significant (Table 2).

The overall mean coronal height from $\mathrm{C}-3$ to $\mathrm{C}-7$ was $6.80 \pm 1.96 \mathrm{~mm}, 6.29 \pm 1.64 \mathrm{~mm}, 6.35 \pm 1.99 \mathrm{~mm}, 6.29 \pm$ $1.78 \mathrm{~mm}$, and $6.30 \pm 1.88 \mathrm{~mm}$, respectively. There were no statistically significant differences between boys and girls at any level. The mean coronal height in patients younger than 8 years of age for levels C3-7 was $6.21 \pm 1.34 \mathrm{~mm}$, $5.78 \pm 1.12 \mathrm{~mm}, 5.73 \pm 1.25 \mathrm{~mm}, 5.73 \pm 1.16 \mathrm{~mm}$, and 5.71 $\pm 1.06 \mathrm{~mm}$, respectively. For patients 8 years and older, the mean coronal height was $9.16 \pm 2.29 \mathrm{~mm}, 8.41 \pm 1.79$ $\mathrm{mm}, 8.91 \pm 2.42 \mathrm{~mm}, 8.64 \pm 1.99 \mathrm{~mm}$, and $8.81 \pm 2.52$ $\mathrm{mm}$, respectively. All of these differences were statistically significant (Table 2).

\section{Sagittal Width and Height}

The overall mean sagittal width from C-3 to C-7 was $7.40 \pm 2.37 \mathrm{~mm}, 7.38 \pm 1.91 \mathrm{~mm}, 7.29 \pm 1.81 \mathrm{~mm}, 7.04 \pm$ $1.84 \mathrm{~mm}$, and $6.73 \pm 2.15 \mathrm{~mm}$, respectively. There were no statistically significant differences between boys and girls, except at C-7. The mean sagittal width in patients younger than 8 years of age for levels C3-7 was $6.92 \pm$ $1.95 \mathrm{~mm}, 7.06 \pm 1.67 \mathrm{~mm}, 7.02 \pm 1.60 \mathrm{~mm}, 6.73 \pm 1.54$ $\mathrm{mm}$, and $6.38 \pm 1.61 \mathrm{~mm}$, respectively. For patients 8 years and older, the mean sagittal width was $9.54 \pm 2.90$ $\mathrm{mm}, 8.81 \pm 2.28 \mathrm{~mm}, 8.47 \pm 2.20 \mathrm{~mm}, 8.49 \pm 2.41 \mathrm{~mm}$, and $8.35 \pm 3.36 \mathrm{~mm}$, respectively. All of these differences were statistically significant (Table 3 ).

The overall mean sagittal height from C-3 to C-7 was

TABLE 2: Coronal width and height in 70 patients stratified by age and sex*

\begin{tabular}{|c|c|c|c|c|c|c|c|}
\hline Vertebra & All & Male & Female & $p$ Value & Age $<8$ & Age $\geq 8$ & $p$ Value \\
\hline \multicolumn{8}{|c|}{ coronal width } \\
\hline C-3 & $8.67 \pm 1.67$ & $8.78 \pm 1.69$ & $8.44 \pm 1.61$ & 0.2538 & $8.38 \pm 1.38$ & $9.86 \pm 2.14$ & 0.0014 \\
\hline C-4 & $8.68 \pm 1.62$ & $8.80 \pm 1.68$ & $8.44 \pm 1.48$ & 0.2009 & $8.43 \pm 1.37$ & $9.72 \pm 2.14$ & 0.0056 \\
\hline$C-5$ & $8.55 \pm 1.53$ & $8.72 \pm 1.60$ & $8.18 \pm 1.33$ & 0.0383 & $8.28 \pm 1.32$ & $9.69 \pm 1.83$ & 0.0006 \\
\hline C-6 & $8.43 \pm 1.70$ & $8.58 \pm 1.64$ & $8.11 \pm 1.80$ & 0.1421 & $8.05 \pm 1.34$ & $10.04 \pm 2.09$ & $<0.0001$ \\
\hline $\mathrm{C}-7$ & $9.39 \pm 2.26$ & $9.59 \pm 2.26$ & $8.98 \pm 2.21$ & 0.1359 & $8.94 \pm 1.78$ & $11.35 \pm 2.98$ & 0.0004 \\
\hline \multicolumn{8}{|c|}{ coronal height } \\
\hline C-3 & $6.80 \pm 1.96$ & $6.91 \pm 2.01$ & $6.55 \pm 1.85$ & 0.2928 & $6.21 \pm 1.34$ & $9.16 \pm 2.29$ & $<0.0001$ \\
\hline C-4 & $6.29 \pm 1.64$ & $6.39 \pm 1.69$ & $6.09 \pm 1.53$ & 0.3098 & $5.78 \pm 1.12$ & $8.41 \pm 1.79$ & $<0.0001$ \\
\hline$C-5$ & $6.35 \pm 1.99$ & $6.54 \pm 2.04$ & $5.94 \pm 1.82$ & 0.0885 & $5.73 \pm 1.25$ & $8.91 \pm 2.42$ & $<0.0001$ \\
\hline C-6 & $6.29 \pm 1.78$ & $6.44 \pm 1.81$ & $5.97 \pm 1.70$ & 0.1378 & $5.73 \pm 1.16$ & $8.64 \pm 1.99$ & $<0.0001$ \\
\hline $\mathrm{C}-7$ & $6.30 \pm 1.88$ & $6.24 \pm 1.92$ & $6.41 \pm 1.82$ & 0.6119 & $5.71 \pm 1.06$ & $8.81 \pm 2.52$ & $<0.0001$ \\
\hline
\end{tabular}

* All data given as mean $\pm \mathrm{SD}(\mathrm{mm})$. Boldface type indicates statistical significance. 
TABLE 3: Sagittal width and height in 70 patients stratified by age and sex*

\begin{tabular}{cccccccc}
\hline Vertebra & All & Male & Female & p Value & Age $<8$ & Age $\geq 8$ & $p$ Value \\
\hline sagittal width & & & & & & \\
C-3 & $7.40 \pm 2.37$ & $7.55 \pm 2.48$ & $7.07 \pm 2.08$ & 0.2479 & $6.92 \pm 1.95$ & $9.54 \pm 2.90$ & $\mathbf{0 . 0 0 0 1}$ \\
C-4 & $7.38 \pm 1.91$ & $7.54 \pm 2.04$ & $7.03 \pm 1.57$ & 0.1172 & $7.06 \pm 1.67$ & $8.81 \pm 2.28$ & $\mathbf{0 . 0 0 1 0}$ \\
C-5 & $7.29 \pm 1.81$ & $7.38 \pm 1.89$ & $7.08 \pm 1.61$ & 0.3458 & $7.02 \pm 1.60$ & $8.47 \pm 2.20$ & $\mathbf{0 . 0 0 3 9}$ \\
C-6 & $7.04 \pm 1.84$ & $7.14 \pm 1.94$ & $6.81 \pm 1.62$ & 0.3056 & $6.73 \pm 1.54$ & $8.49 \pm 2.41$ & $\mathbf{0 . 0 0 1 9}$ \\
C-7 & $6.73 \pm 2.15$ & $6.95 \pm 2.32$ & $6.23 \pm 1.63$ & $\mathbf{0 . 0 4 0 6}$ & $6.38 \pm 1.61$ & $8.35 \pm 3.36$ & $\mathbf{0 . 0 0 9 4}$ \\
sagittal height & & & & & & \\
C-3 & $6.29 \pm 1.89$ & $6.52 \pm 2.02$ & $5.78 \pm 1.45$ & $\mathbf{0 . 0 1 6 2}$ & $5.86 \pm 1.26$ & $8.22 \pm 2.87$ \\
C-4 & $5.91 \pm 1.59$ & $6.10 \pm 1.63$ & $5.47 \pm 1.40$ & $\mathbf{0 . 0 2 2 6}$ & $5.55 \pm 0.95$ & $7.50 \pm 2.61$ & $\mathbf{0 . 0 0 0 4}$ \\
C-5 & $5.98 \pm 1.67$ & $6.18 \pm 1.74$ & $5.51 \pm 1.40$ & $\mathbf{0 . 0 1 9 0}$ & $5.57 \pm 0.94$ & $7.79 \pm 2.74$ & $\mathbf{0 . 0 0 0 5}$ \\
C-6 & $5.89 \pm 1.66$ & $6.04 \pm 1.70$ & $5.56 \pm 1.52$ & 0.1074 & $5.51 \pm 0.96$ & $7.70 \pm 2.75$ & $\mathbf{0 . 0 0 0 7}$ \\
C-7 & $5.94 \pm 1.69$ & $6.07 \pm 1.79$ & $5.65 \pm 1.40$ & 0.1414 & $5.51 \pm 0.83$ & $7.98 \pm 2.85$ & $\mathbf{0 . 0 0 0 3}$ \\
\hline
\end{tabular}

* All data given as mean \pm SD (mm). Boldface type indicates statistical significance.

$6.29 \pm 1.89 \mathrm{~mm}, 5.91 \pm 1.59 \mathrm{~mm}, 5.98 \pm 1.67 \mathrm{~mm}, 5.89 \pm$ $1.66 \mathrm{~mm}$, and $5.94 \pm 1.69 \mathrm{~mm}$, respectively. There were statistically significant differences between boys and girls at C-3, C-4, and C-5. The mean sagittal height in patients younger than 8 years of age for levels C3-7 was $5.86 \pm$ $1.26 \mathrm{~mm}, 5.55 \pm 0.95 \mathrm{~mm}, 5.57 \pm 0.94 \mathrm{~mm}, 5.51 \pm 0.96$ $\mathrm{mm}$, and $5.51 \pm 0.83 \mathrm{~mm}$, respectively. For patients 8 years and older, the mean sagittal height was $8.22 \pm 2.87$ $\mathrm{mm}, 7.50 \pm 2.61 \mathrm{~mm}, 7.79 \pm 2.74 \mathrm{~mm}, 7.70 \pm 2.75 \mathrm{~mm}$, and $7.98 \pm 2.85 \mathrm{~mm}$, respectively. All of these differences were statistically significant (Table 3 ).

\section{Sagittal Diagonal and Facet Angularity}

The overall mean sagittal diagonal from $\mathrm{C}-3$ to $\mathrm{C}-7$ was $11.76 \pm 3.02 \mathrm{~mm}, 12.40 \pm 2.95 \mathrm{~mm}, 12.86 \pm 3.02 \mathrm{~mm}$, $13.48 \pm 3.32 \mathrm{~mm}$, and $13.64 \pm 3.28 \mathrm{~mm}$, respectively. There were statistically significant differences between boys and girls at C-3 and C-4. The mean sagittal diagonal in patients younger than 8 years of age for levels C3-7 was $10.80 \pm$ $1.83 \mathrm{~mm}, 11.49 \pm 1.94 \mathrm{~mm}, 11.85 \pm 1.92 \mathrm{~mm}, 12.36 \pm 2.04$ $\mathrm{mm}$, and $12.56 \pm 2.10 \mathrm{~mm}$, respectively. For patients 8 years or older, the mean sagittal diagonal was $16.06 \pm 3.53$ $\mathrm{mm}, 16.48 \pm 3.26 \mathrm{~mm}, 17.37 \pm 2.97 \mathrm{~mm}, 18.64 \pm 3.24 \mathrm{~mm}$, and $18.68 \pm 3.08 \mathrm{~mm}$, respectively. All of these differences were statistically significant (Table 4).

The overall mean facet angle from C-3 to C-7 was 46 $\pm 11^{\circ}, 45 \pm 9^{\circ}, 47 \pm 9^{\circ}, 45 \pm 8^{\circ}$, and $41 \pm 7^{\circ}$, respectively. There were statistically significant differences between boys and girls at C-3, C-4, and C-5. The mean facet angle in patients younger than 8 years of age for levels $\mathrm{C} 3-7$ was $44 \pm 8^{\circ}, 44 \pm 7^{\circ}, 46 \pm 8^{\circ}, 45 \pm 8^{\circ}$, and $41 \pm 8^{\circ}$, respectively. For patients 8 years or older, the mean facet angle was $53 \pm 18^{\circ}, 49 \pm 13^{\circ}, 51 \pm 12^{\circ}, 46 \pm 9^{\circ}$, and $41 \pm 7^{\circ}$, respectively; these differences were statistically significant only at C-3. These data are summarized in Table 4.

\section{Discussion}

Roy-Camille ${ }^{12,13}$ first introduced lateral mass screw fixation as a method for cervical spine stabilization in France. Roy-Camille, Magerl, and Louis ${ }^{9,10,13}$ popularized the method, and since then, this technique has become a mainstay of internal cervical fixation and stabilization. Several groups have studied the morphology and anatomy of the adult lateral mass. ${ }^{6,7,11}$ The lateral mass is a quadrangular area of bone that lies lateral to the lamina and in between the facet joints above and below. The anteroposterior diameter of the lateral masses at C-6 and C-7 have been shown to be smaller than the more rostral cervical levels. ${ }^{7}$ In addition to smaller size, the C-7 lateral mass is believed to have a steeper angle compared with more rostral levels. ${ }^{1,15}$ For this reason, many people advocate placing a pedicle screw at C-7. ${ }^{2}$

Abdullah et al. ${ }^{1}$ recently performed a CT morphometric and volumetric analysis of the lateral masses of the adult lower cervical spine. These investigators found that facet angulation decreased from C-5 to C-7, but with the exception of height, the C-7 lateral mass had dimensions that were comparable to the lateral masses of C-5 and C-6. Thus, although a more medial and rostral starting point may be necessary, C-7 lateral mass screws were very feasible in the adult spine. We sought to perform a CT-based morphometric study to evaluate the feasibility of lateral mass screw fixation in the pediatric age group. To the best of our knowledge, no other studies have used CT to evaluate the dorsal cervical vertebral anatomy as it pertains to the use of lateral mass screws in children.

\section{Pediatric Lateral Mass Dimensions}

Our results establish useful guidelines for the placement of subaxial cervical spine (C-3 to C-7) lateral mass screws in the general pediatric population. In our series (Fig. 3), 63 of 700 lateral masses in 70 patients could not accept placement of a lateral mass screw. All of these lateral masses were in children who were younger than 4 years of age and the majority in children who were younger than 1 year of age. The minimum requirements for safe lateral mass screw fixation were at least $10 \mathrm{~mm}$ of sagittal diagonal, assuming that $10 \mathrm{~mm}$ is the shortest commercially available screw length, and any other dimension greater than $4.0 \mathrm{~mm}$, assuming a $0.5 \mathrm{~mm}$ margin of safety.

There were statistically significant age-related differ- 
Morphometric analysis of lateral masses

TABLE 4: Sagittal diagonal and facet angularity in 70 patients stratified by age and sex*

\begin{tabular}{lccccccc}
\hline \multicolumn{1}{c}{ Vertebra } & All & Male & Female & p Value & Age $<8$ & Age $\geq 8$ & $p$ Value \\
\hline sagittal diagonal (mm) & & & & & & & \\
C-3 & $11.76 \pm 3.02$ & $12.10 \pm 3.15$ & $11.00 \pm 2.57$ & $\mathbf{0 . 0 3 3 2}$ & $10.80 \pm 1.83$ & $16.06 \pm 3.53$ & $<0.0001$ \\
C-4 & $12.40 \pm 2.95$ & $12.75 \pm 3.05$ & $11.61 \pm 2.55$ & $\mathbf{0 . 0 2 5 8}$ & $11.49 \pm 1.94$ & $16.48 \pm 3.26$ & $<0.0001$ \\
C-5 & $12.86 \pm 3.02$ & $13.09 \pm 3.12$ & $12.33 \pm 2.75$ & 0.1562 & $11.85 \pm 1.92$ & $17.37 \pm 2.97$ & $<0.0001$ \\
C-6 & $13.48 \pm 3.32$ & $13.68 \pm 3.35$ & $13.02 \pm 3.25$ & 0.2892 & $12.36 \pm 2.04$ & $18.64 \pm 3.24$ & $<0.0001$ \\
C-7 & $13.64 \pm 3.28$ & $13.99 \pm 3.31$ & $12.84 \pm 3.11$ & 0.0537 & $12.56 \pm 2.10$ & $18.68 \pm 3.08$ & $<0.0001$ \\
facet angularity ( $\left(^{\circ}\right)$ & & & & & & \\
C-3 & $46 \pm 11$ & $44 \pm 10$ & $49 \pm 13$ & $\mathbf{0 . 0 3 4 8}$ & $44 \pm 8$ & $53 \pm 18$ & $\mathbf{0 . 0 2 6 4}$ \\
C-4 & $45 \pm 9$ & $44 \pm 8$ & $48 \pm 11$ & $\mathbf{0 . 0 2 6 7}$ & $44 \pm 7$ & $49 \pm 13$ & 0.0626 \\
C-5 & $47 \pm 9$ & $46 \pm 8$ & $50 \pm 11$ & $\mathbf{0 . 0 1 5 7}$ & $46 \pm 8$ & $51 \pm 12$ & 0.0614 \\
C-6 & $45 \pm 8$ & $44 \pm 7$ & $46 \pm 10$ & 0.3343 & $45 \pm 8$ & $46 \pm 9$ & 0.4708 \\
C-7 & $41 \pm 7$ & $41 \pm 7$ & $42 \pm 8$ & 0.3513 & $41 \pm 8$ & $41 \pm 7$ & 0.9719 \\
\hline
\end{tabular}

* All data given as mean \pm SD. Boldface type indicates statistical significance.

ences noted in axial width and height, coronal width and height, sagittal width and height, and sagittal diagonal at all cervical vertebral levels. At C-3, there was a statistically significant age-related difference in facet angle; otherwise, there were no significant age-related differences in facet angle from C-4 to C-7. Overall, there were not statistically significant sex-related differences noted in axial width and height, coronal width and height, sagittal width and height, sagittal diagonal, and facet angularity at any cervical vertebral levels. Although there were some statistically significant differences at isolated levels for some of these measurements, these differences were not clinically significant.
The measure of facet angularity and sagittal diagonal height are of particular importance to the pediatric spine surgeon. ${ }^{1}$ The facet angle decreased by approximately $5^{\circ}$ for each level moving caudally from C-5 to C-7, and was consistently larger in girls than boys. Except for C-3, facet angle was unchanged between younger children and older children. On the other hand, sagittal diagonal height increased by approximately $0.5 \mathrm{~mm}$ at each successive caudal level, was consistently smaller in girls than boys, and was significantly smaller in younger children than older children. These data imply that as lateral mass screws are placed at more caudal levels, it is possible that the most effective and safe starting points would be more superior
A

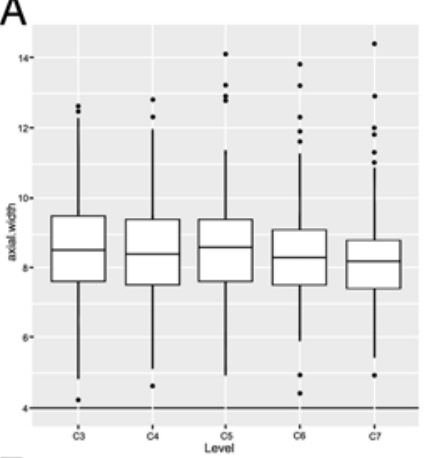

E

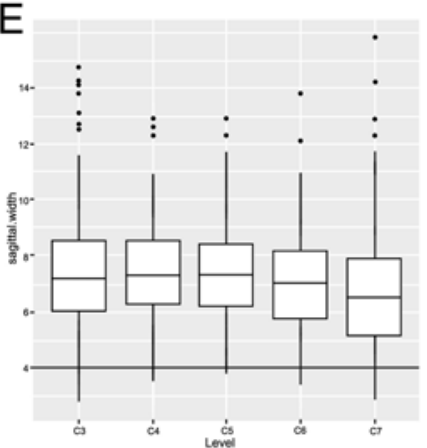

B

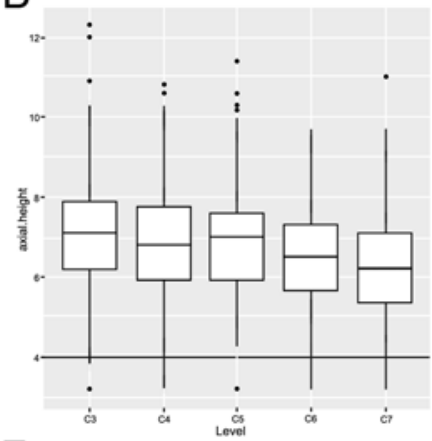

$\mathrm{F}$

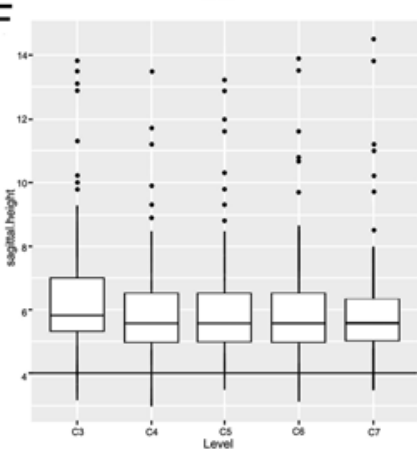

C

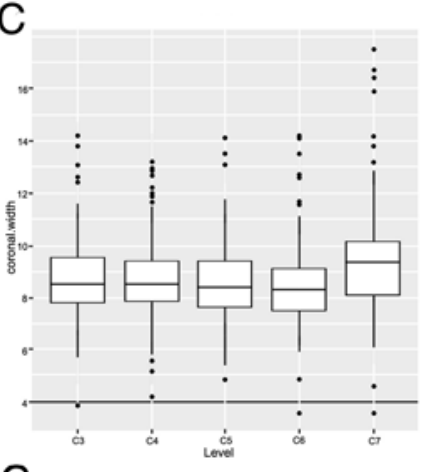

G

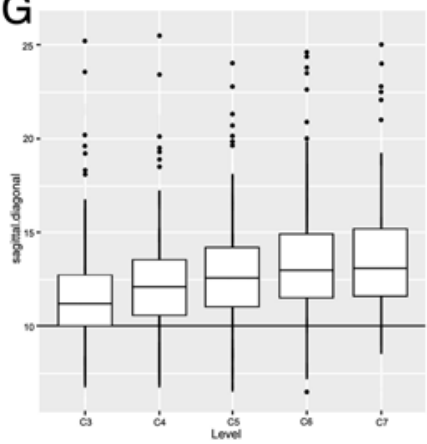

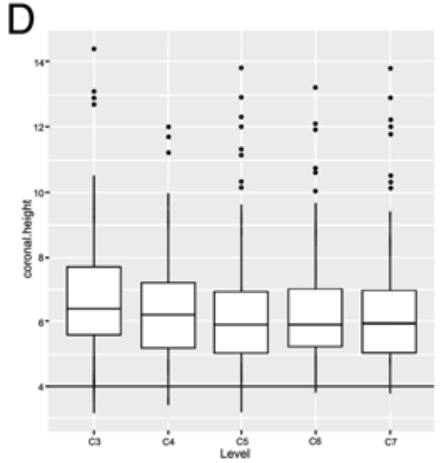

$\mathrm{H}$

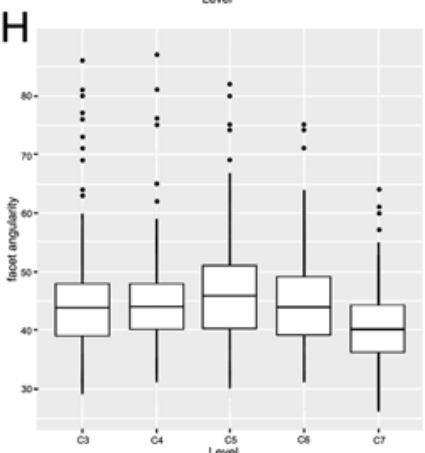

Fig. 3. Boxplots of each measured dimension at each cervical level. Boxes represent the interquartile range $(25 \%-75 \%)$, with a horizontal line representing the median. The dots and vertical lines represent the full range. 
and medial compared with those used for the modified Magerl technique at higher levels and in adult patients.

\section{Comparison of Pediatric and Adult Lateral Mass Measurements}

Differences exist between our study and a recently published adult radiographic study. Abdullah et al. ${ }^{1}$ reported progressive increase in axial height, coronal height, and sagittal diagonal height at successively caudal levels C-5, C-6, and C-7. The same authors reported progressive decrease in axial width, coronal width, sagittal height, sagittal width, and facet angulation at successively caudal levels.

In our study, we found a trend toward a progressive increase in coronal width and sagittal diagonal, moving from the middle to the lower cervical spine. We found a trend toward progressive decreasing dimensions in axial width and height, coronal height, sagittal width and height, and facet angulation. Our lateral mass measurements compare with adult dimensions, especially measurements of sagittal diagonal height and facet angulation, values that provide the surgeon with a better understanding of an appropriate trajectory for lateral mass screw placement. ${ }^{1}$

\section{Conclusions}

Lateral mass fixation is established, feasible, and efficacious in the adult spine. Little clinical or radiographic data has been published to establish its safety and efficacy in the pediatric spine. Our study shows that subaxial cervical spine lateral mass screws may be used in the majority of pediatric patients. All patients $\geq 4$ years of age can accept lateral mass screws based on our measurements. More importantly, the facet angulation of the cervical spine decreases by approximately $5^{\circ}$ moving caudally toward C-7, while facet height increases. These measurements may imply a more medial and rostral starting point for more caudal cervical levels and a steeper screw trajectory as compared with adult techniques. Preoperative thin-slice CT is essential for identifying children in whom this technique is applicable and for planning screw trajectories.

\section{Disclosure}

The authors report no conflict of interest concerning the materials or methods used in this study or the findings specified in this paper.

Author contributions to the study and manuscript preparation include the following. Conception and design: Jea. Acquisition of data: Jea. Analysis and interpretation of data: Jea. Drafting the article: Jea, Al-Shamy, Cherian. Critically revising the article: all authors. Reviewed submitted version of manuscript: all authors Approved the final version of the manuscript on behalf of all authors: Jea. Statistical analysis: Jea. Administrative/technical/material support: Jea. Study supervision: Jea.

\section{References}

1. Abdullah KG, Steinmetz MP, Mroz TE: Morphometric and volumetric analysis of the lateral masses of the lower cervical spine. Spine (Phila Pa 1976) 34:1476-1479, 2009

2. An HS, Gordin R, Renner K: Anatomic considerations for plate- screw fixation of the cervical spine. Spine (Phila Pa 1976) 16 (10 Suppl):S548-S551, 1991

3. Barrey C, Mertens P, Jund J, Cotton F, Perrin G: Quantitative anatomic evaluation of cervical lateral mass fixation with a comparison of the Roy-Camille and the Magerl screw techniques. Spine (Phila Pa 1976) 30:E140-E147, 2005

4. Chin KR, Eiszner JR, Roh JS, Bohlman HH: Use of spinous processes to determine drill trajectory during placement of lateral mass screws: a cadaveric analysis. J Spinal Disord Tech 19:18-21, 2006

5. Deen HG, Birch BD, Wharen RE, Reimer R: Lateral mass screw-rod fixation of the cervical spine: a prospective clinical series with 1-year follow-up. Spine J 3:489-495, 2003

6. Ebraheim NA, Hoeflinger MJ, Salpietro B, Chung SY, Jackson WT: Anatomic considerations in posterior plating of the cervical spine. J Orthop Trauma 5:196-199, 1991

7. Ebraheim NA, Xu R, Challgren E, Yeasting RA: Quantitative anatomy of the cervical facet and the posterior projection of its inferior facet. J Spinal Disord 10:308-316, 1997

8. Hedequist D, Proctor M, Hresko T: Lateral mass screw fixation in children. J Child Orthop 4:197-201, 2010

9. Jeanneret B, Magerl F, Ward EH, Ward JC: Posterior stabilization of the cervical spine with hook plates. Spine (Phila Pa 1976) 16 (3 Suppl):S56-S63, 1991

10. Nazarian SM, Louis RP: Posterior internal fixation with screw plates in traumatic lesions of the cervical spine. Spine (Phila Pa 1976) 16 (3 Suppl):S64-S71, 1991

11. Pait TG, McAllister PV, Kaufman HH: Quadrant anatomy of the articular pillars (lateral cervical mass) of the cervical spine. J Neurosurg 82:1011-1014, 1995

12. Roy-Camille R, Saillant G, Bertreaux D: Early management of spinal injuries, in McKibbin B (ed): Recent Advances in Orthopaedics. Edinburgh: Churchill-Livingstone, 1979, pp 57-87

13. Roy-Camille R, Saillant G, Laville C, Benazet JP: Treatment of lower cervical spinal injuries-C3 to C7. Spine (Phila Pa 1976) 17 (10 Suppl):S442-S446, 1992

14. Sairyo K, Sakai T, Higashino K, Tamura T, Katoh S, Yasui N: Cervical and upper thoracic screwing for spinal fusion: strategy for its safe insertion to avoid major complications. Arch Orthop Trauma Surg 129:1447-1452, 2009

15. Sekhon LH: Posterior cervical lateral mass screw fixation: analysis of 1026 consecutive screws in 143 patients. J Spinal Disord Tech 18:297-303, 2005

16. Stemper BD, Marawar SV, Yoganandan N, Shender BS, Rao RD: Quantitative anatomy of subaxial cervical lateral mass: an analysis of safe screw lengths for Roy-Camille and Magerl techniques. Spine (Phila Pa 1976) 33:893-897, 2008

17. Swank ML, Sutterlin CE III, Bossons CR, Dials BE: Rigid internal fixation with lateral mass plates in multilevel anterior and posterior reconstruction of the cervical spine. Spine (Phila Pa 1976) 22:274-282, 1997

18. Xu R, Ebraheim NA, Yeasting R, Wong F, Jackson WT: Anatomy of C7 lateral mass and projection of pedicle axis on its posterior aspect. J Spinal Disord 8:116-120, 1995

19. Xu R, Haman SP, Ebraheim NA, Yeasting RA: The anatomic relation of lateral mass screws to the spinal nerves. A comparison of the Magerl, Anderson, and An techniques. Spine (Phila Pa 1976) 24:2057-2061, 1999

Manuscript submitted March 7, 2012.

Accepted August 14, 2012.

Please include this information when citing this paper: published online September 14, 2012; DOI: 10.3171/2012.8.SPINE12767.

Address correspondence to: Andrew Jea, M.D., Texas Children's Hospital, 6621 Fannin Street, CCC 1230.01, 12th Floor, Houston, Texas 77030.email: ahjea@texaschildrenshospital.org. 